Full length article

\title{
Sleeping with the frenemy: How restricting 'bedroom use' of smartphones impacts happiness and wellbeing
}

\author{
Nicola Hughes*, Jolanta Burke \\ School of Psychology, University of East London, Stratford Campus, Water Lane, London E15 4LZ, UK
}

\section{A R T I C L E I N F O}

\section{Article history:}

Received 11 November 2017

Received in revised form

26 January 2018

Accepted 27 March 2018

Available online 29 March 2018

\section{Keywords:}

Smartphone

Social media

Social overload

Subjective wellbeing

Cyber psychology

Positive psychology

\begin{abstract}
A B S T R A C T
Smartphone technology has dramatically changed the way people interact with the physical and online world. Research shows both positive and negative impacts of smartphone and social platform use. Positive outcomes relate to social capital and engagement, while negative impacts result from compulsive usage, negative comparisons and the stress of being 'always on'. Little evidence is available regarding wellbeing impacts of smartphone use at particular times of day. This study measures the impact of overnight smartphone use on wellbeing. Experimental group participants abstained from smartphone use in the bedroom for one week. The Subjective Happiness Scale, Quality of Life Scale, Smartphone Addiction Scale and Intensity \& Time Affect Survey were issued at the beginning and end of the week. Paired sample T-Tests compared pre and post intervention participant surveys scores. It was hypothesised that subjective wellbeing would increase. In three out of four measures (SAS-SV, SHS and QOLS) the hypothesis was upheld, although impacts were relatively small. 93.6\% of experimental group participants said they "might' or "would" consider self-imposing intervention conditions moving forward, suggesting that participants experienced greater benefits not measurable through the questionnaires selected. Some qualitative analysis supports exploration of findings. Further research to explore other wellbeing impacts is encouraged.
\end{abstract}

(C) 2018 Elsevier Ltd. All rights reserved.

\section{Introduction (INC. Literature review)}

\subsection{Introduction}

The 21st century is the era of the smartphone. At the end of 2016, four out of five UK adults owned a smartphone, with some $69 \%$ of people looking at their phone within half an hour of waking, and $58 \%$ within half an hour of going to sleep at night (Marsden \& Lee, 2016). Therefore, phones have become humans' constant companions.

The prevalence and low cost of smartphone technology (Sapacz, Rockman, \& Clark, 2016) resulted in increased use of technology and individuals' subsequent 24/7 accessibility to the outside world, via email, phone-call, text message, Whatsapp and other social media (McFarland and Ployhart, 2015). This, in turn, caused instances of 'technostress', which refers to the stress induced by the communication and information overload associated with modern technologies (Ragu-Nathan, Tarafdar, Ragu-Nathan, \& Tu, 2008).

\footnotetext{
* Corresponding author

E-mail address: nicolajanehughes@hotmail.com (N. Hughes).
}

Coupled with the ill-effects of 'social overload' (Maier, Laumer, Eckhardt, \& Weitzel, 2012), caused by the relentlessness of our 'always on' culture (Turkle, 2011), smartphones can have a negative effect on individuals' wellbeing. Considering that social networking sites, such as Facebook are the most frequently used apps on a smartphone (Nielsen, 2015; Shen, 2016), the focus of the literature review is on the impacts of social media.

\subsection{Negative effects of smartphone use}

The accessibility of smartphones has been identified as a key factor in excessive internet use (EIU). Social media sites specifically, along with gaming sites, are predictors of excessive smartphone and internet use, leading to negative impacts such as increased stress, emotional instability and poor sleeping patterns (Škařupová, Ólafsson, \& Blinka, 2015).

Social networking sites (which include Facebook, Whatsapp, Twitter, QQ WeChat, Instagram and many others) are reported as the most popular applications of internet use (Xanidis \& Brignell, 2016). A study on the impact of smartphones and social media on students reported that $75 \%$ of students spend between 1 and $5 \mathrm{~h}$ 


\section{Glossary of terms}

Social Media Any form of online communication tool or platform, including (but not limited to) Whatsapp, Instagram, Facebook, text messages, email and online forums

Smartphone Any type of internet-enabled device through which one engages with social media and the online world, including (but not limited to) smartphones, laptops, tablets and wearable tech

Bedroom Use The use of smartphones whilst in the bedroom, especially in bed

Blue Light The bright polychromatic light emitted by smartphone screens

Social Capital The level of social resource a person has available to them via their personal network and relationships

per day on social networking sites. $85 \%$ of students surveyed described social networking sites as 'very time-consuming' and said that the time could be better used (Al-Harrasi \& Al-Badi, 2014). Another study found that median time spent on social media for nineteen to thirty-two year olds was $61 \mathrm{~min}$ (Levenson, Shensa, Sidani, Colditz, \& Primack, 2016). Ofcom has reported that $87 \%$ of young adults (18-29 years) use their smartphones to visit social media sites (Orzech, Grandner, Roane, \& Carskadon, 2016) and that $76 \%$ of all internet users in the UK have at least one social media profile (Adults' media use and attitudes, 2018). It is clear that much of the time spent on smartphones is dedicated to 'social media', a term which refers to sharing, scrolling, posting, gaming and consuming online content, as well as chatting to contacts (AlHarrasi \& Al-Badi, 2014). Smart Insights' global social media research report found Facebook to be the run-away leader of social networking sites, with an astonishing 1870 million active users worldwide; approximately 870 million more users than its closest competitor, Whatsapp (“|Top Social Network sites by number of active users 2017 | Smart Insights, 2018). It is prudent therefore, when discussing the wellbeing impacts of smartphone and social media use, to look a little deeper in to the impacts associated with Facebook specifically.

One thematic analysis on Facebook use highlights a number of shared stressors, including negative emotions such as 'aggravation' caused by the onslaught of 'unwanted content', feelings of having 'no privacy' and a sense of being trapped by the platform, with users feeling unable to unsubscribe, or feeling compelled to keep checking it (Fox and Moreland, 2015). Relationship stressors included arguments regarding who partners were speaking to online, while other negative outcomes included feelings of inferiority or jealousy, by users negatively comparing their lives to the online lives of others.

These qualitative findings are supported by many quantitative research pieces showing that, for example, subjective wellbeing declines in both the short and the long term, in positive correlation with the time spent on Facebook (Kross et al., 2013). In adolescents, we see social isolation, incidents of cyber-bullying and depression as reported impacts of social online engagement on mental wellbeing (Best, Manktelow, \& Taylor, 2014).

Spending time on social media sites such as Facebook can create negative emotions (Wise, Alhabash, \& Park, 2010). This is in part due to the idealised versions of themselves that people tend to present online (Chou \& Edge, 2012). People are known to use social media not just for communication but also as a way of seeking attention and validation (Seidman, 2014). For this reason, social media profiles tend to contain the more positive or most impressive aspects of peoples' lives, with users sharing things which show themselves in the best light (Chou \& Edge, 2012). Profiles are mostly 'highlight reels' (Steers, Wickman, \& Acitelli, 2014) rather than balanced or accurate reflections of people's lives and, since there is no real-world interaction, users are unable to gauge nonverbal signals which might contradict the tone of posts, meaning users can be unaware that they are seeing a distorted version of the truth (Chou \& Edge, 2012).

Social media sites can encourage us to engage in negative or uninvited social comparisons which make us feel bad (Steers et al., 2014). One study showed that the longer someone has had a Facebook account for, the more likely they are to believe that life is unfair, and that other people's lives are better or happier than their own (Chou \& Edge, 2012). Interestingly, there is a positive correlation between time spent on Facebook and levels of depression, regardless of whether users assess that they are doing 'better' or 'worse' than other people (Steers et al., 2014). These studies imply that people will have a more realistic view of other people if they reduce online communication and increase real-life interactions.

Prohibiting bedroom smartphone use necessarily restricts social media engagement and may help to mitigate its negative impacts. Reducing time spent engaging with internet-enabled devices overnight seems to be an appropriate place to start exploring how we can increase wellness and reduce the negative impacts associated with smartphone technology and social media use.

Another phenomenon of the smartphone era is the large scale 'emotional contagion' (Coviello et al., 2014; Kramer, Guillory, \& Hancock, 2014) which can occur in the cyber space of social networks. Though the contagion itself is neither good nor bad, users should be aware that when entering cyber space, they open themselves up to the prevailing mood of the masses, which has the potential to significantly affect their own mood (Coviello et al., 2014). Since users cannot control what others post or what is delivered to their feed, there is always a risk that logging on will expose users to pictures or information which create negative emotions (Steers et al., 2014). Examples of this might include distressing or aggravating content following terror attacks or elections, or personal posts which spark a negative emotional response, such as a photo of an ex-partner with their new flame.

Other consequences of smartphone use include impacts on sleep quality, which can be negatively affected by engaging with smartphones before bed (Marsden \& Lee, 2016), while using digital media close to bedtime has been shown to negatively impact both quality and quantity of sleep (Orzech et al., 2016). Furthermore, there is a negative relationship between screen usage, sleep and academic performance (Peiró-Velert et al., 2014). A study of school children found an association between children who had the most screen time and those who had shorter sleep durations, while those who slept with a small screen in the room had significantly less perceived rest or sleep (Falbe et al., 2015). Technology use has been shown to be high amongst young adults (18-29 years) in the hour before going to sleep, despite evidence that using digital media within this period leads to poor quality sleep and disrupted sleep patterns (Orzech et al., 2016).

A large-scale study of 1763 US young adults (19-32 years) found that using social media before bed was independently associated with disturbed sleep. Importantly, the more frequently individuals checked their social media before bed, the greater their sleep disturbances were likely to be (Levenson, Shensa, Sidani, Colditz, \& Primack, 2017). In another study of adults aged 18-58, it was discovered that use of social networking sites is highly associated with poor sleep outcomes and 'cognitive failures' throughout the day (Xanidis \& Brignell, 2016). Smartphone use for work late at 
night has been shown to negatively impact users the next day, in terms of energy levels and work engagement, as a result of its impact on sleep quantity (Lanaj, Johnson, \& Barnes, 2014).

Moreover, studies have shown that melatonin onset time is affected by screen use (Wood, Loughran, \& Stough, 2006) and that exposure to screens just before bed impacts the first stages of sleep (Chellappa, Steiner, Oelhafen, Lang, \& Götz, 2013). This means that users will find they sleep later and have more difficulty dosing off than if they had not been looking at their screen before bed.

The research findings above support the hypothesis that prohibiting bedroom use of smartphones will increase wellbeing amongst participants, as it might improve their sleep outcomes and daytime mental functioning.

\subsection{Addiction/compulsive use}

Habitual or compulsive engagement with the smartphone is likened to an array of behavioural addictions (Sapacz et al., 2016) and has a detrimental effect on wellbeing. It is associated with decreased academic performance (Hawi \& Samaha, 2016), life satisfaction and academic success, and heightened levels of perceived stress (Samaha \& Hawi, 2016). Higher levels of smartphone use (as measured on the smartphone addiction scale) are associated with increased anxiety and depression, and decreased quality of sleep (Demirci, Akgönül, \& Akpinar, 2015). Apart from mental illness, the over-use of Facebook also negatively correlates with mental health. Individuals scoring highly on the Bergen Facebook Addiction Scale (BFAS) reported reduced levels of satisfaction with life, subjective well-being, subjective vitality and flourishing (Andreassen, Torsheim, Brunborg, \& Pallensen, 2012). Therefore, the effect of excessive smartphone use extends to various measures of mental health.

In addition to the negative effect of smartphone engagement, high-use phone users experience more distress during leisure time on their phone than low level users, who are also less bored, showed more preference for challenge and can see benefits and opportunities more readily than their high user counter parts (Lepp, Li, Barkley, \& Salehi-Esfahani, 2015). Thus, the impact of smartphone use permeates through different aspects of people's lives.

Habitual smartphone use has been shown to lead to addictive use (van Deursen et al., 2015), meaning that the more time people spend on their smartphones, the more at risk they are of developing an addictive relationship with them. Some types of individual are more at risk of developing smartphone addiction than others. Specifically, introverts and people who rank lower in measures of emotional-stability can find themselves more at risk (Kuss, van Rooij, Shorter, Griffiths, \& van de Mhee, 2013a, 2013b).

\subsection{Contrary impacts and findings}

In contrast to the negative effects of social media, Facebook can also serve as a vehicle for creating and maintaining relationships and as such can be a positive force for social connectedness (Grieve, Indian, Witteveen, Tolan, \& Marrington, 2013), increasing users' personal networks and social capital (Chan, 2015; Ellison, Steinfield, \& Lampe, 2007). Since social connectedness and feeling like part of a community have been shown to correlate with positive affect and subjective wellbeing (Davidson \& Cotter, 1991; Kenyon \& Carter, 2010), it's evident that smartphones and social media platforms can bring about positive effects for users, if used in community building and enhancing ways.

Lonely people tend to have fewer Facebook friends and less overlap between real-world friends and Facebook friends (Jin, 2013), adding weight to the notion that online social engagement can be a positive experience which expands feelings of community and connectedness (Grieve et al., 2013). Perceived social support, safe identity experimentation and increased self-esteem associated with social capital have also emerged as benefits to adolescent users (Best et al., 2014). However, while using social media can be an avenue for alleviating loneliness, lonely people do still report less satisfaction with the Facebook platform than less lonely people (Jin, 2013). This may be due to the fact that the impact of the site is more strongly linked to user personality, life circumstances and manner of engagement, rather than they are inherent outcomes of time spent engaging.

Though multiple stressors can ensue from social overload (Maier et al. 2012), perceived stress reduction has also been shown to be elicited from ritualistic use of tablets or smartphones, with users experiencing a calming escape from the day when using their device in this way (Leung, 2015). This evidence that smartphones can be used in ways that reduce stress further suggests that it is not smartphones definitively, but the manner in which they are used that determines their positive or negative impacts.

Flow is a state of full engagement, and a component of a good life (Seligman, 2011) that can be experienced when using Facebook (Mauri, Cipresso, Balgera, Villamira, \& Riva, 2011). The combination of 'high positive valance' (intrinsic attraction) and high levels of arousal (Mauri et al. 2011) characterised by core flow state may explain the habitual, in some cases compulsive (Ryan, Chester, Reece, \& Xenos, 2014) use of the platform as it has the ability to draw us in to a place where time is lost. Flow is commonly accepted as a positive state or experience, however, the state does not necessarily imply pleasure or enjoyment (Csikszentmihalyi, 1990). Regarding flow during smartphone use, it should be acknowledged that users may still experience negative emotional reactions to content (Wise et al., 2010) and regretful feelings of time-wasting (Kross et al., 2013) either during or after engaging with the site. This adds further complexity to positive and negative impacts of smartphone usage by raising the question of whether experiencing flow in an activity which raises negative feelings can still be viewed as positive experience.

\subsection{Importance of usage behaviours}

As with most tools, it is not the tool itself but the way that tool is used which has the biggest impact on wellbeing. Research must seek to understand the impacts of behaviour types and identify tools or interventions which increase benefits or reduce negative impacts on users.

Social media can be used in different ways, with different impacts. Individuals who use social media platforms in 'active' (Verduyn et al., 2015) or 'communicative' (Chan, 2015) ways are shown to experience the benefits of increased social capital (Ellison et al., 2007) and do not experience any negative impact on their affective wellbeing as a result of the engagement (Verduyn et al., 2015). In contrast, users who engage with social media platforms in a 'non-communicative' (Chan, 2015) or 'passive' way, show decreased affective wellbeing and other negative emotional impacts (Verduyn et al., 2015). Verduyn et al.'s study (2015) assigned 'active' and 'passive' Facebook usage instructions to groups of individuals and measured their affective wellbeing before, immediately after and a day after the intervention. Passive users showed a significant drop in affective wellbeing the day after use, whereas active users show no such drop. One limitation of this study is that the usage style is contrived and difficult to control as a real-world activation, however, the results do suggest that interventions which limit passive smartphone use are likely to enhance wellbeing and reduce negative affect. It's conceivable that passive use might occur more in the hours before bed and upon waking, so research in 
to smartphone use at particular times is a pertinent next step in this exploration.

Ohly and Latour (2014) found when investigating evening phone use for work, that it was not simply whether or not the phone was used in the evening for work, but whether the individual was intrinsically motivated to use it at that time and in that way, which made the difference to their positive affect or otherwise. This further propagates the notion that smartphone engagement is problematic when use is compulsive or coercive, rather than free willed. Interventions which seek to reduce compulsive use or interrupt coercive engagement patterns may increase wellbeing.

Regarding separation from the smartphone, anxiety related to smartphone deprivation only increases when the smartphone is in sight but cannot be used (Sapacz et al. 2016), suggesting that adage 'out of sight, out of mind' might be pertinent to usage considerations. Interventions, which prohibit smartphone use without removing the physical object may inadvertently cause increased anxiety, whereas interventions which require leaving the phone in another room, for example, may have greater positive impacts.

In a study conducted by Borrelli (2015) no significant change in partner satisfaction was found when couples were required to turn their smartphones off for $2 \mathrm{~h}$ a day together, over a two-week period. While there were limitations to this study, including the number of participants and the state of their pre-existing relationships, the findings suggest that more investigation is needed for us to understand exactly where negative impacts of smartphone usage can be found, and what interventions can then be forged to mitigate them.

Taking all into consideration, smartphone use can have both negative and positive effects on wellbeing. While research suggests that reducing the levels of technology usage and social media engagement can have a positive effect on wellbeing (Chellappa et al., 2013) and training in awareness and usage of Information and Communication Technologies (ICTs) can mitigate the effects of 'technostress' (Ragu-Nathan et al., 2008), little is known the impact of smartphone use at particular times of day, and there is a lack of research on whether abstaining from smartphone usage late at night and early in the morning impacts smartphone addiction levels or subjective wellbeing. Thus, the current study aims to investigate the impact of restricting bedroom use of smartphones on the wellbeing of individuals.

\section{Material and methods}

\subsection{Participants}

The study was carried out with 95 participants, divided randomly into the experimental $(n=49)$ and control $(n=46)$ groups. Most were female $(n=64,67 \%)$ and the majority were based in the UK $(n=88,92.6 \%)$. The study group included a full range of participant ages, with the majority of participants being classed as millennials; 'Gen Z, iGen, or Centennials: Born 1996 and later' ( $n=1,<1.0 \%$ ), 'Millennials-Born 1977-1995' ( $n=69,72.7 \%$ ), 'Generation X-Born 1965-1976' $(n=10,10.5 \%)$, 'Baby BoomersBorn 1946-1964' $(n=13,13.7 \%)$ and 'Traditionalists or Silent Generation: Born 1945 and before' ( $n=2,2.1 \%)$. Participants were recruited using a snowball sampling via social networking sites.

\subsection{Measures}

Four questionnaires were used in the current study; the Subjective Happiness Scale (SHS: Lyubomirsky \& Lepper, 1999), the Quality of Life Scale (QOLS: Flanagan, 1982), the Smartphone Addiction Scale - Short Version (SAS-SV: Kwon, Kim, Cho, \& Yang,
2013), and the Intensity and Time Affect Survey (ITAS: Diener, Smith, \& Fujita, 1995). In addition to these quantitative measures, a deductive approach to qualitative research was undertaken, whereby six qualitative questions were asked of experimental participants following the intervention, to offer further insight in to the participant experience.

\subsubsection{SHS}

This is a four-item questionnaire that assesses people's happiness using a seven-point Likert scale. Statements include 'In general, I consider myself ... ' with number one meaning 'Not a very happy person', number seven meaning 'A very happy person'. Users select the number which most accurately reflects where they sit along the spectrum specified. The Cronbach's alpha for SHS demonstrates reliability at $\langle=0.86$ (Lyubomirsky \& Lepper, 1999), with the current study showing $\langle=0.87$.

\subsubsection{QOLS}

This is a 16-item questionnaire that measures how satisfied people are with the conditions of their life at present. A seven point Likert scale is used, with number one meaning 'Delighted', number seven meaning 'Terrible' and the mid-point being 'Mixed'. Participants rate their level of satisfaction with sixteen areas of life, including, 'Close friends' and, 'Work - job or in home.' The Cronbach's alpha for QOLS past studies ranged between $\langle=0.82$ to $\langle=0.92$ (Burckhardt \& Anderson, 2003). In this study, reliability was very high at $\langle=0.9$.

\subsubsection{SAS-SV}

This is a 10-item questionnaire that examines risk for developing smartphone addiction. The statements relate to smartphone use, for example 'Using my smartphone longer than intended'. Users select how far that statement is appropriate to their own smartphone usage experience on a six-Likert scale. Number one represents 'strongly disagree' and number six represents 'strongly agree'. The Cronbach's alpha from past research demonstrated high reliability of $\langle=0.91$ (Kwon et al., 2013). In this study, Cronbach's alpha coefficient was $\langle=0.78$.

\subsubsection{ITAS}

ITAS is used to explore how frequently participants experience particular emotions during the week preceding the survey. It contains a list of twenty-four emotions, including joy, fear and affection. It is assessed on a seven-Likert scale representing the frequency of each stated emotion, with one meaning 'never', seven meaning 'always'. In this study, Cronbach's alpha coefficient was $\langle=0.73$.

The survey can also be used to look at various sub scales; the love subscale $(\langle=0.92)$, the joy subscale $(\langle=0.89)$ and the positive emotion subscale $(\langle=0.94)$. For this study we are interested in looking at the positive emotion subscale.

\subsection{Procedure}

After the initial survey data was submitted at day one, the intervention week began. Control group participants were instructed to continue with their smartphone use as normal. Experimental group participants were required not to use their phone in their bedroom for one week.

At day eight participants were issued with a survey link via Qualtrics. They were required to complete the same for self-report psychological questionnaires detailed above and were asked a small number of qualitative questions regarding their experience, to give the researcher context which might be necessary to understand the reason for the results and to explain any outliers at the 
point of data analysis. Post-intervention questions differed between the two groups. Control group participants were asked, for example, if any big life events had happened to them during the week. This was to give the researcher some visibility over potential 'history effects' (Haslam \& McGarty, 2014) which may have impacted the control participant results. Experimental group participants were asked questions including how difficult they found it to stick to the rules of the intervention, and whether they would consider continuing on with the conditions of the intervention of their own accord, after the imposed conditions were lifted. The purpose of these questions was to add colour to the quantitative data collection and give the researcher some insight in to the participants' experience of the intervention.

\section{Results}

Paired sample T-Tests were conducted to compare pre and post intervention scores, for both experimental and control conditions. Table 1 shows mean score and standard deviation results for the two intervention time points (pre and post intervention week scores) in the case of both the experimental and the control group, across all four surveys. The paired T-test result and significance scores between time points for each group are also shown.

\subsection{Subjective happiness}

There was a significant difference in the SHS scores for the experimental group from Time $1(M=18.0, S D=4.07)$ to Time 2 $(M=19.3, S D=4.05), t(48)=3.17, \mathrm{p}<0.003$ (two-tailed). The mean increase of the scores was -1.33 with a $95 \%$ confidence interval ranging from -2.17 to -0.486 .

The eta squared statistic $\left(\eta^{2}=0.17\right)$ indicated a small effect size.

There was no significant difference in the SHS scores for the control group from Time $1(M=20.7, S D=4.00)$ to Time 2 $(M=20.7, S D=3.8), t(45)=0.060, \mathrm{p}<0.952$ (two-tailed). The mean increase of the scores was 0.022 with a $95 \%$ confidence interval ranging from -71 to 0.75 .

\subsection{Quality of life}

There was a significant difference in the QOLS scores for the experimental group from Time $1(M=82.8, S D=12.2)$ to Time 2 $(M=86.2, S D=10.6), t(48)=3.99, \mathrm{p}<0.000$ (two-tailed). The mean increase of the scores was -3.81 with a $95 \%$ confidence interval ranging from -5.71 to -1.88 .

The eta squared statistic $\left(\eta^{2}=0.25\right)$ indicated a small to moderate effect size.

There was no significant difference in the QOLS scores for the control group from Time $1(M=85.0, S D=12.2)$ to Time 2 $(M=84.5, S D=11.2), t(45)=0.516, \mathrm{p}<0.608$ (two-tailed). The mean increase of the scores was 0.522 with a $95 \%$ confidence interval ranging from -1.52 to 2.56 .

\subsection{Smartphone addiction}

There was a significant difference in the SAS-SV scores for the experimental group from Time $1(M=14.5, S D=5.37)$ to Time 2 $(M=12.9, S D=4.99), t(48)=2.24, \mathrm{p}<0.030$ (two-tailed). The mean decrease of the scores was 1.63 with a $95 \%$ confidence interval ranging from 0.17 to 3.1 .

The eta squared statistic $\left(\eta^{2}=0.094\right)$ indicated a small effect size.

There was no significant difference in the SAS-SV scores for the control group from Time $1(M=13.0, S D=4.57)$ to Time 2 $(M=12.5, S D=4.67), t(45)=1.24, \mathrm{p}<0.647$ (two-tailed). The mean decrease of the scores was 0.52 with a $95 \%$ confidence interval ranging from -0.33 to 1.37 .

\subsection{Intensity and time affect - positive emotions subscale}

There was no significant difference in the ITAS Positive Emotions Subscale scores for the experimental group from Time $1(M=38.1$, $S D=9.26)$ to Time $2(M=39.8, S D=7.77), t(48)=1.85, \mathrm{p}<0.071$ (two-tailed). The mean increase of the scores was -1.67 with a $95 \%$ confidence interval ranging from -3.50 to 0.148 .

There was no significant difference in the ITAS Positive Emotions Subscale scores for the control group from Time $1(M=39$., $S D=8.39)$ to Time $2(M=40, S D=3.8), t(45)=-1.22, \mathrm{p}<0.230$ (two-tailed). The mean increase of the scores was -1.02 with a $95 \%$ confidence interval ranging from-2.71 to 0.67 .

\subsection{Participant reactions}

In the post-intervention questions the experimental group were asked, 'Would you consider continuing to restrict bedroom use of your mobile/internet-enabled device?' Of the 49 participants in that group, 2 did not answer the question. Of the 47 respondents to this question, $74.5 \%(n=35)$ said they would consider continuing the conditions, $19.1 \%(n=9)$ said they might consider continuing the conditions and only $6.4 \%(n=3)$ said that they would not consider continuing to restrict bedroom phone usage of their own accord from now on.

Experimental group participants were also asked an openended question: 'What changes, if any, have you observed in yourself as a result of the intervention?'. A thematic analysis of their responses was conducted, which revealed four key themes of participant experience. The first two themes related to the changes they observed in their well-being and quality of life, the other two themes referred to the differences in how they spend the time before and after going to sleep. The details of the themes and subthemes can be found in Table 2 .

Improved sleeping experiences - this theme emerged as having

Table 1

Paired samples T-Test: Pre and post intervention week surveys comparison.

\begin{tabular}{|c|c|c|c|c|c|c|c|c|c|c|c|c|}
\hline & \multicolumn{6}{|c|}{ Experimental $(\mathrm{n}=49)$} & \multicolumn{6}{|c|}{ Control $(n=46)$} \\
\hline & \multicolumn{2}{|c|}{ Pre-test } & \multicolumn{2}{|c|}{ Post-test } & \multicolumn{2}{|c|}{$\begin{array}{l}\text { Paired sample T- } \\
\text { Test, statistical } \\
\text { significance }\end{array}$} & \multicolumn{2}{|c|}{ Pre-test } & \multicolumn{2}{|c|}{ Post-test } & \multicolumn{2}{|c|}{$\begin{array}{l}\text { Paired sample T- } \\
\text { Test, statistical } \\
\text { significance }\end{array}$} \\
\hline & M & SD & M & SD & $t$ & $p$ & M & SD & M & SD & $t$ & $p$ \\
\hline SHS & 18. & 4.07 & 19.3 & 4.05 & -3.17 & 0.003 & 20.7 & 4. & 20.7 & 3.8 & 0.060 & 0.952 \\
\hline QOLS & 82.8 & 12.2 & 86.6 & 10.6 & -3.99 & 0.000 & 85. & 12.2 & 84.5 & 11.2 & 0.516 & 0.608 \\
\hline SAS-SV & 14.5 & 5.37 & 12.9 & 4.99 & 2.24 & 0.030 & 13. & 4.57 & 12.5 & 4.67 & 1.24 & 0.223 \\
\hline ITAS Positive Emotions Subscale & 38.1 & 9.26 & 39.8 & 7.77 & -1.85 & 0.071 & 40. & 3.8 & 40.0 & 3.8 & -1.22 & 0.230 \\
\hline
\end{tabular}

${ }^{*} \mathrm{p}<0.01$ and ${ }^{* *} \mathrm{p}<0.001$. 
the strongest impact on participants, who have improved their ability to fall asleep faster and reported better quality of sleep. Here are some examples of participants' quotes: "I slept sounder", "I slept better at night", "I fell asleep quicker", "I remembered my dreams!"

Reduced anxiety and improved wellbeing - another improvement that participants observed related to their self-reported reduction of anxiety and improvement of well-being. Specifically, they mentioned feeling better immediately, as a result of the intervention, i.e. during the night and after waking up, as well as noting the effect of the intervention on their entire week. Here are some examples of participants' quotes: "calmer last thing at night and first thing in the morning", "less anxious when waking up in the night", "a feeling of calm throughout the week", "happier and not as anxious/self-conscious".

Improved personal relationships - the third theme focused on what the participants have done with the extra time and attention they had available, when not using their smartphone before going to bed. Specifically, they mentioned that their relationships have improved as a result of their intervention. Firstly, they reported thinking about and focusing more on their life partners; secondly, they communicated more with their partners. Here are some examples of participants' quotes: "More focus between me and my partner", "more focus on my relationship", "longer conversations with my partner", "I thought about the people I actually have close relationships with".

Less time-wasting and more focus on other things - the final theme emerging from the experimental group related to having the time to do other things participants enjoyed, which are grouped under having some "me" time to do what they want. Also, due to the changes in their sleeping hygiene, they reported having more energy in the morning, which allowed them to get up earlier and use their extra time in the morning on other enjoyable activities. Here are some examples of participants' quotes: "reading more in bed", "more thinking/pondering time', "out of bed and about earlier", "getting ready quicker in the morning".

\section{Conclusions}

\subsection{Summary and evaluation of findings}

The goal of this study was to explore the impact of the restriction of 'bedroom use' of smartphones on participants' subjective wellbeing, in four distinct areas of wellbeing, i.e. Subjective Wellbeing (SWB), Quality of Life (QOL) and Addiction, as well as Intensity and Time Affect (ITAS). The results have shown small, but significant differences between time 1 and time 2 for the experimental group across SWB, QOL and Addiction, whilst no statistically significant changes were found in the control group. Whilst the findings are promising, further research needs to be carried out that extends the intervention over a longer period of time, which may result in a larger effect size.

Given the relatively small reported impacts of the intervention, it is interesting to note that the vast majority of experimental participants (93.6\%) said they "would" or "might" consider selfimposing the restriction after the intervention was over. This suggests that the study may not have used the best measures for identifying the specific benefits of this type of smartphone restriction, but that there are some important user benefits to be explored in future research.

Participant answers to the question, 'What changes, if any, have you observed in yourself as a result of the intervention?' give some clear indication as to where such benefits may be found. The reported benefits included improvements in sleep quality and quantity, improvements to personal relationships, less timewasting, more focus on other activities and increased feelings of calm. These findings are very encouraging, showing a clear picture of positive impacts and experiences which might have been missed by the focus or form of the quantitative measures.

Most findings, from the current study, are in line with research showing that reduced screen time (Lanaj et al., 2014), lower levels of smartphone usage (Maier et al. 2012) and less time spent of social media (Chou \& Edge, 2012; Steers et al. 2014) positively correlate with beneficial impacts such as increased subjective happiness reduced stress and greater wellbeing (Kross et al., 2013).

Considering the wealth of research regarding technostress (Ragu-Nathan et al., 2008), social overload (Maier et al., 2012) and other negative impacts issuing from smartphone and social media usage (Fox \& Moreland, 2015), it is perhaps surprising that the impacts experienced by participants in the experimental group were not more dramatic.

There could be a number of reasons for this. Firstly, digital connectivity and social media usage also have a number of benefits to individuals, including social interaction (Ellison et al., 2007) and feelings of connectedness and community (Grieve et al., 2013). Smartphone usage has also been shown to have a positive impact on the regulation of negative emotions (Hoffner \& Lee, 2015) when used in ways which enhance connection and social interaction. While experimental group participants may have experienced positive impact from the intervention, those impacts could have been mitigated by reductions in experience of connection and community through restricted social interactions. Participants may have missed out on goodnight messages or other emotional touchpoints, incurring losses as well as gains from the restriction.

Secondly, smartphone use can facilitate experiences of relaxation and escapism (Leung, 2015). When used in this way, positive impacts result from the engagement. Entertainment experiences, such as article reading or TV watching can help regulate negative emotions, so the intervention may have limited escapism or relaxation for some participants, depending on their usual habits (Hoffner \& Lee, 2015). Therefore, future research may specify the type of smartphone use in bed, and the differences in the well-

Table 2

Main themes and subthemes.

\begin{tabular}{|c|c|c|c|}
\hline No & Themes & Subthemes & $\mathrm{N}^{\mathrm{a}}$ \\
\hline 1 & Improved sleeping experiences & $\begin{array}{l}\text { Falling asleep } \\
\text { Quality of sleep }\end{array}$ & 15 \\
\hline 2 & Reduced anxiety and improved wellbeing & $\begin{array}{l}\text { Immediate effect } \\
\text { Medium-term effect }\end{array}$ & 8 \\
\hline 3 & Improved personal relationships & $\begin{array}{l}\text { Thinking about others } \\
\text { Interacting with others }\end{array}$ & 4 \\
\hline 4 & Less time-wasting and more focus on other things & $\begin{array}{l}\text { "Me" time } \\
\text { Energised }\end{array}$ & 10 \\
\hline
\end{tabular}

\footnotetext{
a Prevalence in the participants' group.
} 
being effect between them.

Smartphone usage can be habitual and even addictive (Ryan et al., 2014). Given that addictive behaviour is associated with negative emotions (Chen et al., 2016), this may be one of the reasons as to why no statistically significant differences were reported in the level of affect in the current study. Future research should therefore also consider that participants may have been experiencing frustration or withdrawal during the intervention as a direct result of the imposed conditions. These feelings may have mitigated or cancelled out some of the positive impacts.

Compulsive internet use (CIU) has been shown to negatively impact wellbeing, effecting increases in depression, stress and loneliness (Muusses, Finkenauer, Kerkhof, \& Billedo, 2014). Not only do we see CIU predicting decreases in happiness of users, we also see the correlation in reverse, whereby increased happiness predicts reductions in CIU overtime (Muusses et al., 2014). While such evidence is compelling, it's important to reiterate that this intervention used a representative sample of the adult smartphone-owning population at large, rather than focussing on heavy or problematic phone users. As yet, there is little research in to the impacts of 'regular' or non-problematic smartphone usage, so results must be viewed within the context of the general population, where usage levels, and therefore intervention impacts, will vary.

The research findings overall suggest that there is merit in restricting smartphone usage for the population at large, as well as for compulsive users. However, since the effect sizes were relatively small, more research is needed in to user behaviours and associated impacts in order to establish optimum usage patterns that increase wellbeing and decrease negative impacts.

\subsection{Recommendations for future research}

A full qualitative study using the same experimental conditions could be conducted to analyse the personal experience of the participants and explore further where the wellbeing benefits of this intervention sit. Once there is a greater understanding of the intervention's impacts, the intervention itself could be adapted to incorporate any practical elements of note, and/or different wellbeing measures which more accurately account for the benefits exposed.

Since a high number of participants in the experimental group mentioned sleeping better during the intervention, researchers could conduct a similar intervention with measures relating specifically to sleep quality. Since sleep quality has been shown to have positive impacts on stress response (Bassett, Lupis, Gianferante, Rohleder, \& Wolf, 2015) and subjective wellbeing (Lemola, Ledermann, \& Friedman, 2013), if significant positive impacts result from the intervention, inference could be made that restricting bedroom smartphone usage will positively impact wellbeing, as a by-product of improving sleep quality.

Another iteration could split participants according to whether they sleep alone or with a partner. Since a number of experimental participants mentioned having better focus on their personal relationships following the intervention, it would be interesting to explore whether impacts on wellbeing are greater if pre-sleep time is shared with a partner, but without technology, than if one is alone. It is conceivable that at bedtime smartphone technology could disrupt intimacy between couples, while providing intimacy for singles, through the cyber channels.

As research in to smartphone use and overuse continues, it will be interesting to consider restricting smartphone use at other times of the day, or for particular periods of time, to see if those conditions have significant impacts on people's self-reported measures of wellbeing.
Equally, given that we know of both positive and negative impacts and usage patterns for smartphone users, an intervention prohibiting particular types of smartphone usage, e.g. passive browsing, could be another valuable way for us to increase knowledge and understanding of wellbeing in relation to smartphones.

\subsection{Limitations}

There were a number of limitations to this study, which should be called out for the sake of clarity and to support further development of research. Firstly, since the sample was intended to be representative of the adult smartphone owning population at large, participants were not differentiated between regarding nature or level or smartphone use at the outset of the experiment. This means that both the experimental and the control group contained within them a full spectrum of phone users, from heavy to light. It was reported in a number of the pre and post intervention questions of the experimental group that particular individuals were not in the habit of using their smartphones in their bedroom anyway, meaning that the intervention made no change to their established pattern. Future iterations of this research design could split groups according to their level of phone usage at the outset, to see if more important impacts can be found for particular types of users.

Another limitation of the experiment was that neither a set amount of overnight hours without the smartphone, nor a fixed amount of hours before or after bed were stipulated in conditions. The experimental conditions were designed this way because at the proposal stage, potential participants had fedback resistance to take part in a fixed hours version of the experiment, due to a variety of reasons, such as being out late at night and needing to contact people/transport, or working evenings. The design of the study as conducted, therefore, meant that it could not control for usage times. It is possible that some participants may still have spent extended times periods on their phone prior to bedtime, but in another room and then popped in to their bedroom just before sleep. In this way again, there may not have been a huge change to participants existing smartphone habits.

Further development of this research could prohibit smartphone use for, say, a period of $10 \mathrm{~h}$ surrounding and including the individual's sleeping time. From experience, researchers may struggle to find participants willing to take on this condition, which in itself is perhaps of interest regarding our level of reliance on and attachment to smartphone technology and its impacts on our daily lives.

\section{Conclusion}

Results of this study showed a positive relationship between restricting smartphone use in the bedroom and increased levels of subjective happiness and quality of life. There was a negative relationship between restricting bedroom use of smartphones and one's risk of developing addictive smartphone behaviours.

The impacts reported in those cases were small, but statistically significant, and therefore relevant to a body of research which seeks to explore the impact of smartphones on wellbeing. It is hoped that the continuation of research in this area may identify a revised version of the intervention which prompts larger wellbeing impacts for participants and could be disseminated as an accessible and beneficial positive psychology intervention. Equally, further research should be done in to how other areas of wellbeing are impacted by bedroom smartphone use, such as sleep quality and partner satisfaction, so that we might gain more insight in to those areas too. 


\section{References}

Adults' media use and attitudes. (2018) (pp. 6-7). Retrieved from https://www. ofcom.org.uk/_data/assets/pdf_file/0020/102755/adults-media-use-attitudes2017.pdf.

Al-Harrasi, A., \& Al-Badi, A. (2014). The impact of social networking: A study of the influence of smartphones on college students. Contemporary Issues In Education Research (CIER), 7(2), 129. https://doi.org/10.19030/cier.v7i2.8483.

Andreassen, C. S., Torsheim, T., Brunborg, G. S., \& Pallensen, S. (2012). Development of a Facebook addiction scale. Psychological Reports, 110(2), 501-517.

Bassett, S., Lupis, S., Gianferante, D., Rohleder, N., \& Wolf, J. (2015). Sleep quality but not sleep quantity effects on cortisol responses to acute psychosocial stress. Stress, 18(6), 638-644.

Best, P., Manktelow, R., \& Taylor, B. (2014). Online communication, social media an adolescent wellbeing: A systematic narrative review. Children and Youth Services Review, 41, 27-36.

Borrelli, J. S. (2015). Exploring the influence of smartphone technology within the context of Marriage: An intervention study. Digital Comms @ George Fox University, $167,1-47$

Burckhardt, C. S., \& Anderson, K.,L. (2003). The quality of life scale (QOLS): Reliability, validity, and utilization. Health and Quality of Life Outcomes, 1, 60. https:// doi.org/10.1186/1477-7525-1-60.

Chan, M. (2015). Mobile phones and the good life: Examining the relationships among mobile use, social capital and subjective wellbeing. New Media and Society Journal, 17(1), 96-113. https://doi.org/10.1177/1461444813516836.

Chellappa, S. L., Steiner, R., Oelhafen, P., Lang, D., \& Götz, T. (2013). Acute exposure to evening blue-enriched light impacts on human sleep. The Journal of Sleep Research, 22, 573-580. https://doi.org/10.1111/jsr.12050.

Chen, L., Yan, Z., Tang, W., Yang, F., Xie, X., \& He, J. (2016). Mobile phone addiction levels and negative emotions among Chinese young adults: The mediating role of interpersonal problems. Computers in Human Behavior, 55, 856-866. https:// doi.org/10.1016/j.chb.2015.10.030.

Chou, H. G., \& Edge, N. (2012). "They Are Happier and Having Better Lives than Am": The Impact of Using Facebook on Perceptions of Others' Lives. Journal of Cyberpsychology, Behaviour and Social Networking, 2, 2. https://doi.org/10.1089/ cyber.2011.0324.

Coviello, L., Sohn, Y., Kramer, A. D. I., Marlow, C., Franceschetti, M., Christakis, N. A., et al. (2014). Detecting emotional contagion in massive social networks. PLoS One, 9(3), 90315. https://doi.org/10.1371/journal.pone.0090315.

Csikszentmihalyi, M. (1990). Flow: The psychology of optimal experience. New York: Harper \& Row.

Davidson, W., \& Cotter, P. (1991). The relationship between sense of community and subjective well-being: A first look. Journal of Community Psychology, 19(3), $246-253$.

Demirci, K., Akgönül, M., \& Akpinar, A. (2015). Relationship of smartphone use severity with sleep quality, depression, and anxiety in university students. Journal of Behavioral Addictions, 4(2), 85-92.

van Deursen, A., Bolle, C., Hegner, S., \& Kommers, P. (2015). Modeling habitual and addictive smartphone behavior. The role of smartphone usage types, emotional intelligence, social stress, self-regulation, age, and gender. Computers in Human Behavior, 45, 411-420.

Diener, E., Smith, H., \& Fujita, F. (1995). The personality structure of affect. Journal of personality and Social Psychology, 50, 130-141.

Ellison, N. B., Steinfield, C., \& Lampe, C. (2007). The benefits of Facebook "Friends:" social capital and college students' use of online social network sites. Journal of Computer-Mediated Communication, 12, 1143-1168. https://doi.org/10.1111/ j.1083-6101.2007.00367.x.

Falbe, J., Davison, K., Franckle, R., Ganter, C., Gortmaker, S., Smith, L., et al. (2015). Sleep duration, restfulness, and screens in the sleep environment. Pediatrics, 135(2), 367-375.

Flanagan, J. C. (1982). Measurement of quality of life: Current state of the art. Archives of Physical Medicine and Rehabilitation, 63(2), 56-59.

Fox, F., \& Moreland, J. J. (2015). The dark side of social networking sites: An exploration of the relational and psychological stressors associated with Facebook use and affordances. Computers in Human Behavior, 45, 168-176.

Grieve, R., Indian, M., Witteveen, K., Tolan, G. A., \& Marrington, J. (2013). Face-toface or Facebook: Can social connectedness be derived online? Computers in Human Behavior, 29, 604-609.

Haslam, S. A., \& McGarty, C. (2014). Research methods and statistics in psychology (2nd ed.). London, England: SAGE.

Hawi, N., \& Samaha, M. (2016). To excel or not to excel: Strong evidence on the adverse effect of smartphone addiction on academic performance. Computers \& Education, 98, 81-89.

Hoffner, C., \& Lee, S. (2015). Mobile phone use, emotion regulation, and well-being. Cyberpsychology, Behavior, and Social Networking, 18(7), 411-416.

Jin, B. (2013). How lonely people use and perceive Facebook. Computers in Human Behavior, 29(6), 2463-2470.

Kenyon, D., \& Carter, J. (2010). Ethnic identity, sense of community, and psychological well-being among northern plains American Indian youth. Journal of Community Psychology, 39(1), 1-9.

Kramer, A. D. I., Guillory, J. E., \& Hancock, J. T. (2014). Experimental evidence of massive-scale emotional contagion through social networks. Proceedings of the National Academy of Sciences (PNAS), 111, 24. https://doi.org/10.1073 pnas.1320040111.
Kross, E., Verduyn, P., Demiralp, E., Park, J., Lee, D. S., Lin, N., et al. (2013). Facebook use predicts declines in subjective wellbeing in young adults. PLoS One, 8(8), 69841. https://doi.org/10.1371/journal.pone.0069841.

Kuss, D. J., Griffiths, M. D., \& Binder, J. F. (2013b). Internet addiction in students: Prevalence and risk factors. Computers in Human Behavior, 29, 959-966.

Kuss, D. J., van Rooij, A. J., Shorter, G. W., Griffiths, M. D., \& van de Mhee, D. (2013a). Internet addiction in adolescents: Prevalence and risk factors. Computers in Human Behavior, 29, 1987-1996.

Kwon, M., Kim, D., Cho, H., \& Yang, S. (2013). The smartphone addiction Scale: Development and validation of a short version for adolescents. PLoS One, 8(12), 83558.

Lanaj, K., Johnson, R., \& Barnes, C. (2014). Beginning the workday yet already depleted? Consequences of late-night smartphone use and sleep. Organizational Behavior and Human Decision Processes, 124(1), 11-23.

Lemola, S., Ledermann, T., \& Friedman, E. (2013). Variability of sleep duration is related to subjective sleep quality and subjective well-being: An actigraphy study. PLoS One, 8(8), 71292.

Lepp, A., Li, J., Barkley, J., \& Salehi-Esfahani, S. (2015). Exploring the relationships between college students' cell phone use, personality and leisure. Computers in Human Behavior, 43, 210-219.

Leung, L. (2015). Using tablet in solitude for stress reduction: An examination of desire for aloneness, leisure boredom, tablet activities, and location of use. Computers in Human Behavior, 48, 382-391.

Levenson, J., Shensa, A., Sidani, J., Colditz, J., \& Primack, B. (2016). The association between social media use and sleep disturbance among young adults. Preventive Medicine, 85, 36-41. https://doi.org/10.1016/j.ypmed.2016.01.001.

Levenson, J., Shensa, A., Sidani, J., Colditz, J., \& Primack, B. (2017). Social media use before bed and sleep disturbance among young adults in the United States: A nationally representative study. Sleep. https://doi.org/10.1093/sleep/zsx113.

Lyubomirsky, S., \& Lepper, H. S. (1999). A measure of subjective happiness: Preliminary reliability and construct validation. Social Indicators Research, 46(2), 137.

Maier, C., Laumer, S., Eckhardt, A., \& Weitzel, T. (2012). When social networking turns to social overload: Explaining the stress, emotional exhaustion, and quitting behavior from social network sites' users. In AIS Electronic Library: Proceedings (p. 71). http://aisel.aisnet.org/ecis2012/71.

Marsden, E., \& Lee, P. (2016). There's no place like phone: Consumer usage patterns in the era of smartphone. Deloitte Global Mobile Consumer Survey 2016: UK cut [PDF]. Retrieved from http://www.deloitte.co.uk/mobileUK/assets/pdf/DeloitteMobile-Consumer-2016-There-is-no-place-like-phone.pdf.

Mauri, M., Cipresso, P., Balgera, A., Villamira, M., \& Riva, G. (2011). Why is Facebook so Successful? Psychophysiological measures describe a core flow state while using Facebook. The Journal of Cyberpsychology, Behaviour and Social Networking, 14, 12. https://doi.org/10.1089/cyber.2010.0377.

McFarland, L. A., \& Ployhart, R. E. (2015). Social media: A contextual framework to guide research and practice. Journal of Applied Psychology, 100(6), 1653-1677. https://doi.org/10.1037/a0039244.

Muusses, L., Finkenauer, C., Kerkhof, P., \& Billedo, C. (2014). A longitudinal study of the association between Compulsive Internet use and wellbeing. Computers in Human Behavior, 36, 21-28.

Nielsen. (2015). Tops of 2015: Digital. Retrieved from http://www.nielsen.com/us/en/ insights/news/2015/tops-of-2015-digital.html.

Ohly, S., \& Latour, A. (2014). Work-related smartphone use and well-being in the evening. Journal of Personnel Psychology, 13(4), 174-183.

Orzech, K., Grandner, M., Roane, B., \& Carskadon, M. (2016). Digital media use in the $2 \mathrm{~h}$ before bedtime is associated with sleep variables in university students. Computers In Human Behavior, 55, 43-50. https://doi.org/10.1016/j.chb.2015.08. 049.

Peiró-Velert, C., Valencia-Peris, A., Gonzalez, L. M., García-Masso, X., Serra-Año, P., \& Devís-Devís, J. (2014). Screen media usage, sleep time and academic performance in Adolescents: Clustering a self-organizing maps analysis. Public Library of Science, 9(6), 99478.

Ragu-Nathan, T., Tarafdar, M., Ragu-Nathan, B., \& Tu, Q. (2008). The consequences of technostress for end users in Organizations: Conceptual development and empirical validation. Information Systems Research, 19(4), 417-433.

Ryan, T., Chester, A., Reece, J., \& Xenos, S. (2014). The uses and abuses of Facebook: A review of Facebook addiction. Journal of Behavioral Addictions, 3(3), 133-148. https://doi.org/10.1556/JBA.3.2014.016.

Samaha, M., \& Hawi, N. (2016). Relationships among smartphone addiction, stress, academic performance, and satisfaction with life. Computers in Human Behavior, $57,321-325$.

Sapacz, M., Rockman, G., \& Clark, J. (2016). Are we addicted to our cell phones? Computers in Human Behavior, 57, 153-159.

Seidman, G. (2014). Expressing the "True Self" on Facebook. Computers in Human Behavior, 31, 367-372.

Seligman, M. (2011). Flourish. London, UK: Nicholas Brealey Publishing.

Shen, S. (2016). People and their smartphones - Mapping mobile interaction in the modern connected world. Engineering Computations, 33(6), 1642-1658. https:// doi.org/10.1108/EC-06-2015-0153.

Škařupová, K., Ólafsson, K., \& Blinka, L. (2015). The effect of smartphone use on trends in European adolescents' excessive Internet use. Behaviour \& Information Technology, 35(1), 68-74. https://doi.org/10.1080/0144929x.2015.1114144.

Steers, M. N., Wickman, R. E., \& Acitelli, L. K. (2014). Seeing everyone Else's highlight Reels: How Facebook is linked to depressive symptoms. Journal of Social and Clinical Psychology, 33(8), 701-731. 
Top Social Network sites by number of active users 2017 | Smart Insights. (2018). Smart insights. Retrieved 19 January 2018, from https://www.smartinsights. com/social-media-marketing/social-media-strategy/new-global-social-mediaresearch/attachment/top-social-network-sites-by-number-of-active-users2017/.

Turkle, S. (2011). Alone Together: Why we expect more from technology and less from each other. New York, USA: Basic Books.

Verduyn, P., Seungjae Lee, D., Park, J., Shablack, H., Orvell, A., Bayer, J., et al. (2015). Passive Facebook usage undermines affective Wellbeing: Experimental and longitudinal evidence. Journal of Experimental Psychology, 144(2), 480-488. https://doi.org/10.1037/xge0000057.

Wise, K., Alhabash, S., \& Park, H. (2010). Emotional responses during social information seeking on Facebook. Journal of Cyberpsychology, Behaviour and Social Networking, 13, 5. https://doi.org/10.1089=cyber.2009.0365.

Wood, A. W., Loughran, S. P., \& Stough, C. (2006). Does evening exposure to mobile phone radiation affect subsequent melatonin production? International Journal of Radiation Biology, 82(2), 69-76.

Xanidis, N., \& Brignell, C. (2016). The association between the use of social network sites, sleep quality and cognitive function during the day. Computers In Human Behavior, 55, 121-126. https://doi.org/10.1016/j.chb.2015.09.004. 